\title{
Community structure and distribution of ground beetles (Coleoptera: Carabidae) in Sobaeksan National Park, Korea
}

\author{
EuiJeong Hong ${ }^{1+}$, Youngjin Kim ${ }^{1+}$, Jong-Chul Jeong ${ }^{1}$, Seung-Ho Kang ${ }^{1}$, Jong-Kook Jung ${ }^{2}$ and Sang-Wook Suk ${ }^{1 *}$
}

\begin{abstract}
The ground beetles collected during the investigation period were nine subfamilies, 24 genera, 51 species, and 3504 ground beetles. Species richness was high in Pterostichinae has 24 species (47\%), Harpalinae nine species (17.6\%), Carabinae six species (11.8\%), and Lebiinae three species (5.9\%). Overall dominant species was Synuchus agonus, and dominance index was 0.361. Synuchus agonus was investigated as the dominant species in both Namcheon Valley and Geumseon Valley. Regarding subdominant species, it was Synuchus nitidus (52 individuals, 12.6\%) and Synuchus cycloderus (52 individuals, 12.6\%) in the order in Namcheon Valley, and it was Pterostichus orientalis orientalis (660 individuals, 21.3\%) and Pterostichus audax (378 individuals, 12.2\%) in the order in Geumseon Valley. Total species diversity index of ground beetles in Sobaeksan National Park was 2.917. By area, the number of collected ground beetles was smaller in Namcheon Valley than in Geumseon Valley. Sobaeksan National Park is located at the boundary of northern and southern parts in Korea and is a very important place in terms of geography and climate. Sobaeksan has been designated as a national park, and its ecosystem is relatively preserved well. If continuous investigation of basic data for ground beetles is conducted through long-term monitoring, the data can be used as key data to research mutual relationship with organisms, effects by climate change, and ecosystem change depending on human activities.
\end{abstract}

Keywords: Ground beetle, Monitoring, Species composition, Carabidae

\section{Introduction}

Insects are a very huge taxon taking up more than half of biodiversity known on earth (Speight et al. 1999). Insects have evolved in various forms as the member of natural ecosystem (Cho 2013) and are a core biota in terms of ecosystem's structure and function (Crawley 1983). The number of biospecies identified so far is estimated to be about 1 million to 1.2 million, and approximately 1000 species are found a year (Andrews 1923). However, it is estimated that there will be more species that have yet to be found. Global warming affects vast areas by causing not only the change of natural ecosystem but also the regional imbalance of water resources and food resources, sea level rise, heavy rain, and drought, from the ecological, social, and biological

\footnotetext{
*Correspondence: suk615@hanmail.net

${ }^{\dagger}$ Equal contributors

${ }^{1}$ National Park Research Institute, Wonju 26441, Korea

Full list of author information is available at the end of the article
}

aspects. Coleopteran playing a pivotal ecological role in the forest ecosystem accounts for $40 \%$ of entire insects, and some 400,000 species of the Coleopteran are known to exist in the world. About 33,000 species of Carabidae taking up most of ground beetles are recorded globally, and Carabidae is the biggest taxon out of Coleopteran. Except for Cicindelidae, 21 subfamilies, 110 genera, and 531 species of Carabidae are recorded (Park and Paik 2001; Park 2004). Ground beetles are a taxon inhabiting based on soil and litter layer and have diverse ecological statuses including a species preying other insects or earthworms, a species eating dead animal's corpse, a species eating decayed fallen leaves, and a species eating mushrooms such as fungi (Lövei and Sunderland 1996). Therefore, ground beetles play an important role in food chain, and they are reported to be recognized as an important natural enemy in the agricultural environment (Kromp 1999; Holland 2002). The hind wings of most species of beetle subfamily are degraded in many cases, 
and their migration ability is weak, and thus, diversity may decrease, in case the severance and change of habitat is caused (Niemelä et al. 2000). Since these taxa's species composition and density vary according to the vegetation, soil status, temperature and rainfall of habitat, and the inhabitation of mammals and amphibians, an analysis of species diversity and ecological habit can indirectly evaluate the ecological environment within the habitat concerned according to climate change. In Korea, however, research on ground beetles is insufficient compared to that on other taxa, and just some researches according to species distribution and altitude of some habitat are reported (Jung et al. 2011; Jung et al. 2012; Jung et al. 2015). In this regard, this study has been carried out to offer basic information on the species composition, distribution change of ground beetles within habitat, and community structure depending on climate change by using pitfall trap.

\section{Materials and methods Study sites}

In order to investigate ground beetles in Sobaeksan National Park, this study investigated through selection of each point around Namcheon Valley on the northern slope and around Geumseon Valley on the southern slope (Table 1, Fig. 1), which are judged to have high biodiversity, in consideration of mountain's topography, environmental characteristics, and major vegetation structure.

\section{Collecting method}

Ground beetles were collected by pitfall trap because of the characteristics of activity at the ground. In both sites, three sets (one set contained of nine pitfall traps) were placed and spaced $50 \mathrm{~m}$ apart from each other. The pitfall traps were used with plastic cups $(300 \mathrm{ml}, 9-\mathrm{cm}$ diameter and 10-cm depth) and covered with rain-cover. Pitfall traps were filled with preservative solution (200 ml, 95\% ethyl alcohol to 95\% ethylene glycol = 1:1) and were replaced every 2 weeks. Traps were collected approximately every 2 weeks between March and November in 2015.

\section{Data analysis}

Shannon and Weaver (1949) diversity index $\left(\mathrm{H}^{\prime}\right)$, Pielou's (1975) evenness index (EI), Simpson (1949) dominance index (DI), and Margalef's (1958) richness index (RI) were calculated on the basis of the quantitative samples.

(1) Diversity index $\left(\mathrm{H}^{\prime}\right)=-\sum(\mathrm{ni} / \mathrm{N}) \operatorname{Ln}(\mathrm{ni} / \mathrm{N})$

(2) Evenness index $(\mathrm{EI})=\mathrm{H}^{\prime} / \operatorname{In}(\mathrm{S})$

(3) Dominance index (DI) $=\Sigma(\mathrm{Pi})^{2}$

(4) Richness index $(\mathrm{RI})=(\mathrm{S}-1) / \mathrm{In}(\mathrm{N})$

\section{Results and discussion}

Species diversity of ground beetles in Sobaeksan National Park

The ground beetles collected during the investigation period were nine subfamilies, 24 genera, 51 species, and 3504 ground beetles (Table 2). In terms of investigation point, nine subfamilies, 21 genera, 38 species, and 413 ground beetles were collected in Namcheon Valley, and seven subfamilies, 16 genera, 36 species, and 3091 ground beetles in Geumseon Valley. In a previous study, Jung et al. investigated ground beetles by altitude in Sobaeksan National Park for 3 years from 2007, and there were 7 subfamilies, 17 genera, 32 species, and 3259 ground beetles. In this study, additional species have been investigated, because the investigation points were located on the southern and northern slopes, the investigation started from spring, and the distance between the investigation points was relatively far. There were five unidentified species that needed additional research among 51 species (Amara sp, Harpalus sp, Synuchus sp, Trichotichnus sp. 1, Trichotichnus sp. 2). Therefore, 46 ground beetles species distributed in the Sobaeksan National Park were investigated, except for the unidentified species. Although two more subfamilies, five more genera, and two more species were investigated in Namcheon Valley than in Geumseon Valley, 7.5-fold more ground beetles were investigated in Geumseon Valley than in Namcheon Valley in terms of the number of ground beetles. The reason is that the tree stratum consisted of pine trees in Namcheon Valley, while it consisted of Mongolian oaks in Geumseon Valley. Generally, the number of species and ground beetles decrease more in pine tree forest compared to that in broadleaf forest (Lee and Lee 1995). Actually, the density of ground beetles in Geumseon Valley offering more litter layer is conjected to be higher. Since several traps out of the traps in Namcheon Valley are located in the places where waterways are formed in summer, the species composition and the number of ground beetles

Table 1 Location information in Sobaeksan National Park, Korea

\begin{tabular}{|c|c|c|c|c|}
\hline Site & Address & Latitude & Longitude & Altitude (m) \\
\hline Namcheon Valley & Namcheon-ri, Yeongchun-myeon, Danyang-gun, Chungcheongbuk-do, Korea & $37^{\circ} 02^{\prime} 10.45^{\prime \prime}$ & $128^{\circ} 31^{\prime} 04.14^{\prime \prime}$ & 285 \\
\hline Geumseon Valley & Samga-ri, Punggi-eup, Yeongju-si, Gyeongsangbuk-do, Korea & $36^{\circ} 56^{\prime} 25.7^{\prime \prime}$ & $128^{\circ} 29^{\prime} 55.1^{\prime \prime}$ & 678 \\
\hline
\end{tabular}




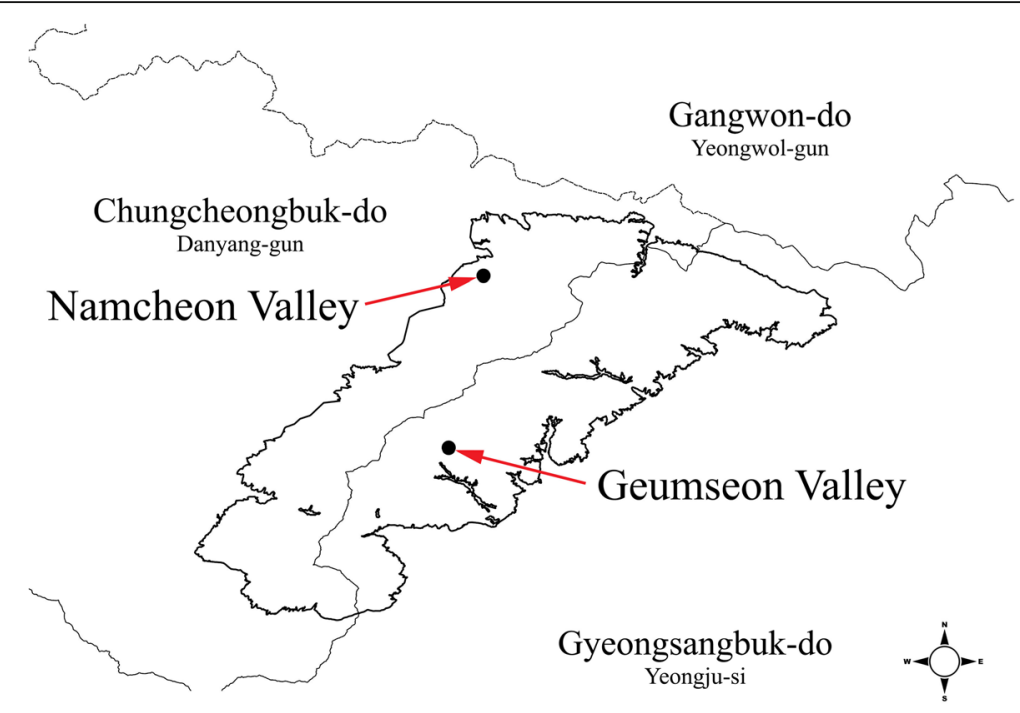

Fig. 1 Survey sites in Sobaeksan National Park, Korea

are judged to be slightly affected by some damage of ground beetles' habitat, due to formation of many waterways within the investigation area.

\section{Dominant species}

As for the number of species by subfamily (Fig. 2), it was indicated in the order of 24 species of Pterostichinae (47\%), nine species of Harpalinae (17.6\%), six species of Carabinae (11.8\%), and three species of Lebiinae (5.9\%). Upon looking at investigation area, the number of species was revealed in the following order in Namcheon Valley: 18 species of Pterostichinae (47.4\%), six species of Harpalinae (15.8\%), and three species of Lebiinae (7.9\%). It was revealed in the following order in Geumseon Valley: 18 species of Pterostichinae (50\%), six species of Harpalinae (16.7\%), and six species of Carabinae (16.7\%). The reason why there were more numbers of species of subfamily Pterostichinae and subfamily Carabinae is that the investigation was carried out, focused on forest (Jung et al. 2011). Concerning the number of ground beetles at genus level (Fig. 3), the genus Synuchus was investigated to dominate with 1838 (52.4\%), followed by 1160 ground beetles of Pterostichus (33.1\%) and 109 ground beetles of Agonum (3.1\%) overall. The genus Synuchus was dominant in both investigation points (Namcheon Valley, 229 individuals; Geumseon Valley, 1609 individuals). Dominance was investigated in the order of Cymindis (6.3\%) and Pterostichus (6\%) in Namcheon Valley, and Pterostichus (36\%) and Agonum (3.2\%) in Geumseon Valley. Upon looking into overall biodiversity in the two investigation points, overall dominant species was Synuchus agonus, and dominance index was 0.361. Synuchus agonus was investigated as the dominant species in both Namcheon Valley (17.2\%) and Geumseon Valley (38.6\%). Regarding subdominant species, it was Synuchus nitidus (52 individuals, 12.6\%) and Synuchus cycloderus (52 individuals, $12.6 \%)$ in the order in Namcheon Valley, and it was Pterostichus orientalis orientalis (660 individuals, 21.3\%) and Pterostichus audax (378 individuals, 12.2\%) in the order in Geumseon Valley. In general, the dominant species of Carabidae in Korean mountainous area are reported to be Synuchus cycloderus and Synuchus nitidus (Yeon et al. 2005), and the two species were ascertained as dominant species in Namcheon Valley. However, Synuchus cycloderus showed 216 ground beetles (7\%) and Synuchus nitidus were 25 ground beetles (0.8\%), and they were investigated as not the largest dominant species in Geumseon Valley. This study confirmed that ground beetles are a taxon hugely affected by the inhabitation environmental characteristics (Thiele 1977), although the two investigation points were within Sobaeksan National Park. Such a result is conjectured to be revealed, due to differences of vegetation structure and altitude in the two investigation points. Upon looking into seasonal activity of dominant species (Fig. 4), only a small number of ground beetles of major dominant species are collected in Namcheon Valley by August, and they rapidly increase from September: all the major dominant species showed the same trend. In Geumseon Valley, however, all major dominant species showed a rapid increasing trend from May to August, but Pterostichus audax and Pterostichus orientalis orientalis showed a downtrend after August. Such a result is judged to be due to different annual generation frequency, and generation and breeding periods depending on species. Since 
Table 2 List of ground beetles collected on Sobaeksan National Park, Korea

\begin{tabular}{|c|c|c|c|c|c|c|}
\hline \multirow[t]{2}{*}{ Scientific name } & \multicolumn{3}{|c|}{$\begin{array}{l}\text { Namcheon Valley } \\
\text { Month }\end{array}$} & \multicolumn{3}{|c|}{$\begin{array}{l}\text { Geumseon Valley } \\
\text { Month }\end{array}$} \\
\hline & $3-5$ & $6-8$ & $9-11$ & $3-5$ & $6-8$ & $9-11$ \\
\hline \multicolumn{7}{|l|}{ Subfamily Brachininae } \\
\hline Brachinus stenoderus Redtenbacher, 1868 & 6 & 3 & 1 & 15 & 7 & \\
\hline Pheropsophus jessoensis Morawitz, 1862 & & 19 & 2 & & & \\
\hline \multicolumn{7}{|l|}{ Subfamily Callistinae } \\
\hline Chlaenius costiger Chaudoir, 1856 & & 1 & & & & \\
\hline Chlaenius naeviger Morawitz, 1862 & & 3 & & & & \\
\hline \multicolumn{7}{|l|}{ Subfamily Carabinae } \\
\hline Aulonocarabus koreanus kwonileeique Deuve, 1992 & & 4 & 1 & & & 1 \\
\hline Aulonocarabus seishinensis seishinensis Lapouge, 1931 & & & & & 6 & \\
\hline Aulonocarabus semiopacus Reitter, 1895 & & & & & 23 & \\
\hline Coptolabrus jankowskii jankowskii Oberthur, 1883 & & & & & 3 & \\
\hline Coreocarabus fraterculus assimilis Kwon et Lee, 1984 & & & & 14 & 2 & \\
\hline Eucarabus sternbergi sobaeksanensis Kwon et Lee, 1984 & 5 & 2 & 1 & 12 & 18 & 4 \\
\hline \multicolumn{7}{|l|}{ Subfamily Harpalinae } \\
\hline Bradycellus fimbriatus Bates, 1873 & & 1 & & & & \\
\hline Harpalus chalcentus Bates, 1873 & & & 1 & & & \\
\hline Harpalus roninus Bates, 1873 & & & & & 1 & 8 \\
\hline Harpalus simplicidens Schauberger, 1929 & & 1 & & & & \\
\hline Harpalus sp.1 & 11 & 9 & & 7 & 12 & \\
\hline Harpalus tridens Morawitz, 1862 & & & & & 1 & \\
\hline Harpalus vicarius Harold, 1883 & & & & & 1 & 5 \\
\hline Trichotichnus sp.1 & 4 & & 2 & & 1 & 3 \\
\hline Trichotichnus sp.2 & 3 & & & 2 & & \\
\hline \multicolumn{7}{|l|}{ Subfamily Lebiinae } \\
\hline Cymindis collaris Motschulsky, 1845 & 12 & 10 & 4 & 4 & 2 & 1 \\
\hline Galerita orientalis Schmidt-Goebel, 1946 & & 1 & & & & \\
\hline Planetes puncticeps Andrewes, 1919 & & & 1 & & & \\
\hline \multicolumn{7}{|l|}{ Subfamily Licininae } \\
\hline Diplocheila zeelandica (Redtenbacher, 1868) & & 2 & & & & \\
\hline \multicolumn{7}{|l|}{ Subfamily Nebriinae } \\
\hline Leistus niger niger Gebler, 1847 & & & 1 & 1 & 1 & \\
\hline Nebria chinensis chinensis Bates, 1872 & 3 & & 18 & 2 & 1 & 2 \\
\hline \multicolumn{7}{|l|}{ Subfamily Pterostichinae } \\
\hline Agonum xestus (Bates, 1883) & 6 & 2 & 1 & 76 & 18 & 6 \\
\hline Colpodes buchanani Hope, 1831 & 2 & & & & & \\
\hline Dolichus coreicus Jedlička, 1936 & & & & & 18 & \\
\hline Pristosia impunctata Sasakawa, Kim, Kim \& Kubota, 2006 & & 5 & 2 & & & \\
\hline Pristosia vigil (Tschitschérine, 1895) & & 2 & 3 & 35 & 19 & 11 \\
\hline Pterostichus audax Tschitschérine, 1895 & 2 & 5 & 1 & 20 & 298 & 60 \\
\hline Pterostichus bellatrix (Tschitschérine, 1895) & & & & & 2 & 3 \\
\hline Pterostichus ishikawaioides Sasakawa, Kim, Kim \& Kubota, 2008 & & & 1 & & 10 & 2 \\
\hline
\end{tabular}


Table 2 List of ground beetles collected on Sobaeksan National Park, Korea (Continued)

\begin{tabular}{|c|c|c|c|c|c|c|}
\hline Pterostichus microcephalus (Motschulsky, 1860) & 1 & 2 & & & & \\
\hline Pterostichus orientalis orientalis Motschulsky, 1845 & 1 & 6 & & 17 & 552 & 91 \\
\hline Pterostichus scurrus (Tschitschérine, 1901) & & & & & 63 & 5 \\
\hline Pterostichus solskyi Chaudoir, 1878 & 6 & & & & & \\
\hline Pterostichus subovatus (Motschulsky, 1860) & & & & 1 & 1 & \\
\hline Pterostichus vicinus Park et Kwon, 1996 & & & & & 9 & 1 \\
\hline Synuchus agonus (Tschitschérine, 1895) & 1 & 9 & 61 & & 484 & 710 \\
\hline Synuchus arcuaticollis Motschulsky, 1860 & & 1 & 5 & & 4 & 10 \\
\hline Synuchus crocatus (Bates, 1883) & & & 27 & & 3 & 11 \\
\hline Synuchus cycloderus (Bates, 1873) & 1 & 4 & 47 & & 138 & 78 \\
\hline Synuchus intermedius Lindroth, 1956 & & & 4 & & & \\
\hline Synuchus melantho (Bates, 1883) & & 10 & 6 & 1 & 72 & 71 \\
\hline Synuchus nitidus (Motschulsky, 1861) & & 3 & 49 & & 8 & 17 \\
\hline Synuchus orbicollis (Morawitz, 1862) & & & & & 1 & \\
\hline Synuchus sp.1 & & 1 & & 1 & & \\
\hline Trigonognatha coreana (Tschitschérine, 1895) & & & 1 & & & \\
\hline \multicolumn{7}{|l|}{ Subfamily Zabrinae } \\
\hline Amara congrua Morawitz, 1862 & 1 & 1 & & 1 & 1 & \\
\hline Amara sp.1 & 1 & & & 1 & 1 & \\
\hline
\end{tabular}
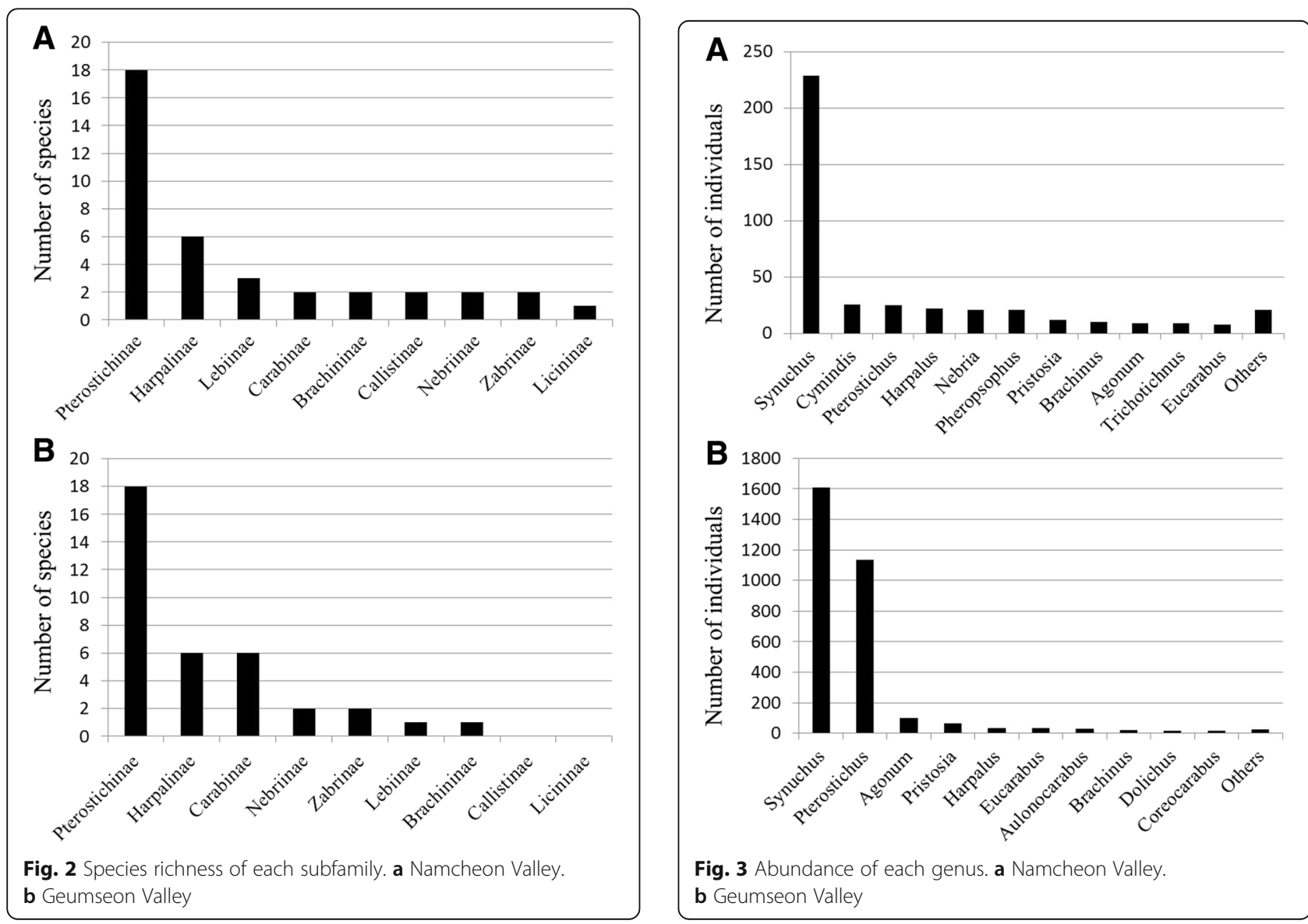

Fig. 3 Abundance of each genus. a Namcheon Valley. b Geumseon Valley 


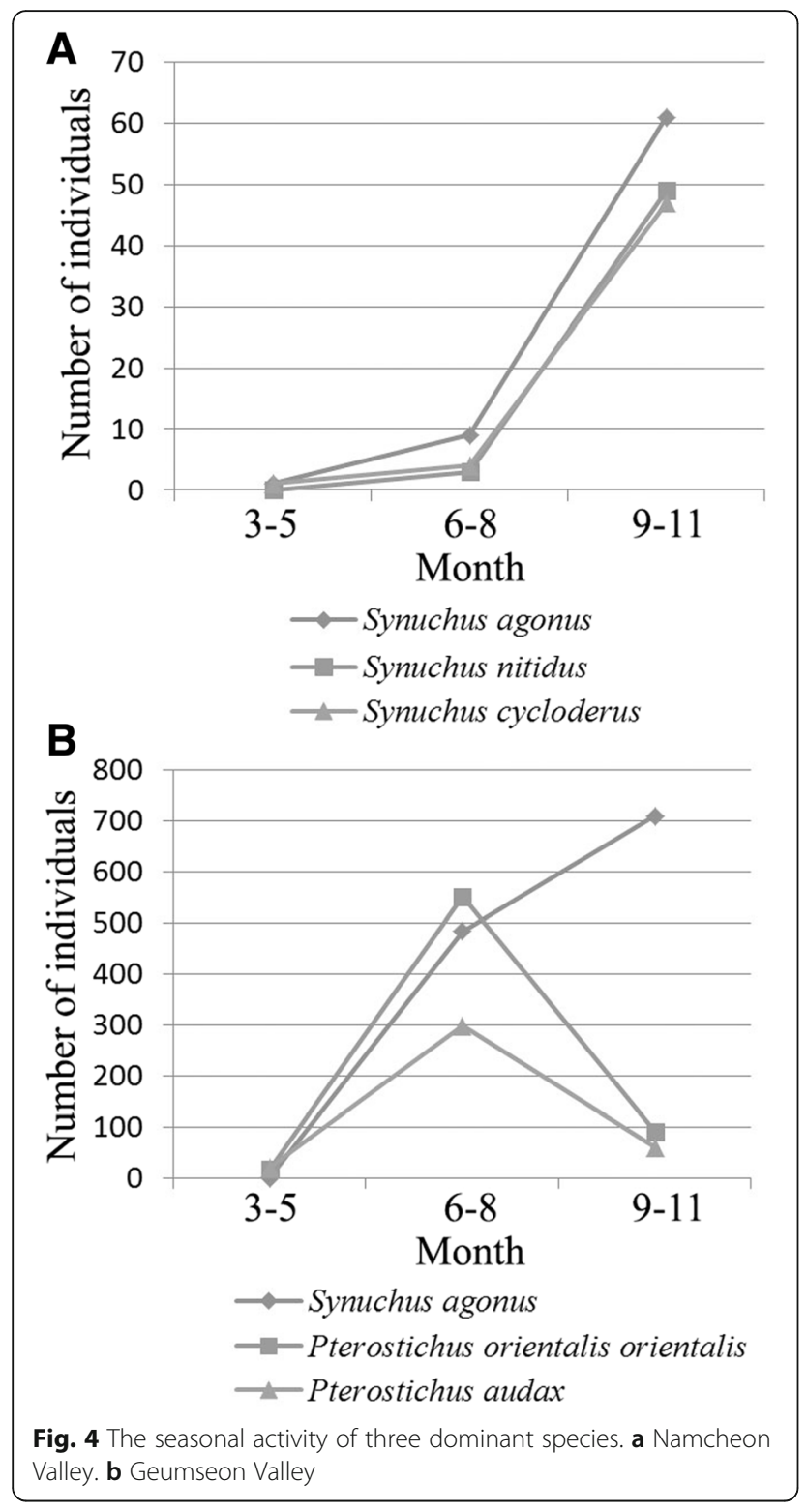

Geumseon Valley is $400 \mathrm{~m}$ higher than Namcheon Valley in altitude, relatively lower temperature is conjected to cause such a result.

\section{Community structure}

The total species diversity index of ground beetles in Sobaeksan National Park was 2.917. By area, the number of collected ground beetles was smaller in Namcheon Valley than in Geumseon Valley; however, the former had relatively higher species diversity than the latter. By period, species diversity rose from March to August and then showed a downtrend from September in Namcheon Valley. However, species diversity was the highest from March through May, and showed a downtrend, as time went by in Geumseon Valley. Especially, the species diversity between September and November was very low at 2.047, and the reason seems that several species were investigated as dominant species. Similar result was revealed in species evenness: the evenness between September and November in Geumseon Valley was very low at 0.466 , and the reason was that the dominant species, Synuchus agonus and Pterostichus orientalis orientalis, took up $72.8 \%$ of the total investigated species. Meanwhile, slightly low evenness was revealed during September and November (0.684), but over 0.8 in evenness was shown before September.

Studies on using Carabidae as a biological indicator to evaluate environmental soundness, such as forest ecosystem disturbance like forest fire or logging and rapid environmental change, are actively conducted overseas recently (Rainio and Niemelä 2003; Pearce and Venier 2006). For those studies to be undertaken, the investigation of ground beetles through long-term monitoring should be carried out. However, only short-term and fragmentary investigations are performed in Korea. Sobaeksan National Park is located at the boundary of northern and southern parts in Korea and is a very important place in terms of geography and climate. Sobaeksan has been designated as a national park, and its ecosystem is relatively preserved well. If continuous investigation of basic data for ground beetles is conducted through long-term monitoring, the data can be used as key data to research mutual relationship with organisms, effects by climate change, and ecosystem change depending on human activities.

\section{Abbreviations}

Dl: Dominance index; El: Evenness index; H': Diversity index; Rl: Richness index

\section{Funding}

This subject is supported by the Korea Ministry of Environment (MOE) as "Public Technology Program based on Environmental Policy (2014000210005)."

\section{Availability of data and materials}

The datasets are available from the corresponding author on a reasonable request.

\section{Authors' contributions}

EJH, YJK, JCJ, SHK, and SWS conducted a survey together during the study period. EJH and YJK drafted the manuscript. JKJ participated in the identification of ground beetles. SWS edited the manuscript draft. All authors read and approved the final manuscript.

\section{Competing interests}

The authors declare that they have no competing interests.

Consent for publication

Not applicable.

Ethics approval and consent to participate Not applicable.

\section{Publisher's Note}

Springer Nature remains neutral with regard to jurisdictional claims in published maps and institutional affiliations. 


\section{Author details}

${ }^{1}$ National Park Research Institute, Wonju 26441, Korea. ${ }^{2}$ Division of Forest

Pests and Diseases, National Institute of Forest Science, Seoul 02455, Korea.

Received: 27 January 2016 Accepted: 5 November 2016

Published online: 17 April 2017

\section{References}

Andrews, H. E. (1923). 22-papers on Oriental Carabidae-10. Annals and Magazine of Natural History, 12, 212-223.

Cho, K. Y. (2013). A study on the distribution of delicate insects to climate change by altitude in Mt. Jeombong. MS Thesis Sang Ji University, Wonju, Korea. (in Korean).

Crawley, M. J. (1983). Herbivory. The dynamics of animal plant interactions (p. 437). Oxford: Blackwell Scientific Publications.

Holland, J. M. (2002). The agroecology of carabid beetles (p. 356). Hampshire: Intercept Ltd. Andover.

Jung, J. K., Kim, S. T., Lee, S. Y., Yoo, J. S., \& Lee, J. H. (2011). Community structure and distribution of ground beetles (Coleoptera: Carabidae) of Mt. Bangtaesan in Gangwon-do, Korea. Korean Journal of Environment and Ecology, 25(3), 307-317 (in Korean).

Jung, J. K., Kim, S. T., Lee, S. Y., Park, C. G., Park, J. K., \& Lee, J. H. (2012). Community structure of ground beetles (Coleoptera: Carabidae) along an altitudinal gradient on Mt. Sobaeksan, Korea. Journal of Asia-Pacific Entomology, 15, 487-494.

Jung, J. K., Lee, J. H., Lee, S. Y., \& Kim, S. T. (2015). Distribution of ground beetles (Coleoptera: Carabidae) in Naejangsan National Park, Korea. Korean Journal of Environment and Ecology, 29(2), 200-209.

Kromp, B. (1999). Carabid beetles in sustainable agriculture: a review on pest control efficacy, cultivation impacts and enhancement. Agriculture, Ecosystem and Environment, 74(1-3), 187-228.

Lee, H. P., \& Lee, G. H. (1995). Species composition and seasonal abundance of ground beetles (Coleoptera: Carabidae) in three different types of forests. Entomological Research Bulletin, 21, 84-90.

Lövei, G. L., \& Sunderland, K. D. (1996). Ecology and behavior of ground beetles (Coleoptera: Carabidae). Annual Review Entomology, 41(1), 231-256.

Margalef, R. (1958). Temporal succession and spatial heterogeneity in phytoplankton. In A. Buzzati-Traverso (Ed.), Perspectives in marine biology (pp. 323-347). Berkeley: Univ. Calif. Press.

Niemelä, J., Kotze, J., Ashworth, A., Brandmayr, P., Desender, K., New, T., Penev, L., Samways, M., \& Spence, J. (2000). The search for common anthropogenic impacts on biodiversity: a global network. Journal of Insect Conservation, $4(1), 3-9$.

Park, J. K. (2004). Subfamily Carabidae in Korea (Coleoptera: Carabidae). Economic insects of Korea 23. Insecta Koreana, 30(Supplement), 99. in Korean.

Park, J. K., \& Paik, J. C. (2001). Family Carabidae. Economic insects of Korean 12. Insecta Koreana, 19(Supplement), 170. in Korean.

Pearce, J. L., \& Venier, L. A. (2006). The use of ground beetles (Coleoptera: Carabidae) and spiders (Araneae) as bioindicators of sustainable forest management: a review. Ecological Indicators, 6(4), 780-793.

Pielou, E. C. (1975). Ecological diversity (p. 165). New York: Wiley.

Rainio, J., \& Niemelä, J. (2003). Ground beetles (Coleoptera: Carabidae) as bioindicators. Biodiversity and Conservation, 12(3), 487-506.

Shannon, C. E., \& Weaver, W. (1949). The mathematical theory of communication. Urbana: University of Illinois Press.

Simpson, E. H. (1949). Measurement of diversity. Nature, 163, 688

Speight, M. R., Hunter, M. D., \& Watt, A. D. (1999). Ecology of insects concepts and applications (p. 340). Oxford: Blackwell Science.

Thiele, H. U. (1977). Carabid beetles in their environments: a study on habitat selection by adaptations in physiology and behaviour (p. 369). Stuttgart: Springer.

Yeon, H. S., Park, J. K., Lee, D. W., \& Chung, K. M. (2005). Distribution of groundbeetles (Coleoptera: Carabidae) in Mt. Gabjangsan, Korea. Asian Journal of Turfgrass Science, 19(1), 47-55 (in Korean with English abstract).

\section{Submit your next manuscript to BioMed Central and we will help you at every step:}

- We accept pre-submission inquiries

- Our selector tool helps you to find the most relevant journal

- We provide round the clock customer support

- Convenient online submission

- Thorough peer review

- Inclusion in PubMed and all major indexing services

- Maximum visibility for your research

Submit your manuscript at www.biomedcentral.com/submit
Biomed Central 